\title{
Chronic kidney disease and fragility fracture
}

\author{
Junichiro James Kazama ${ }^{1}$
}

Received: 26 October 2016/Accepted: 29 November 2016/Published online: 23 December 2016

(C) The Author(s) 2016. This article is published with open access at Springerlink.com

\begin{abstract}
Osteoporosis is defined simply as "a skeletal disorder characterized by compromised bone strength predisposing to an increased risk of fracture. Thus, any bone lesion that causes fragility fracture is osteoporosis, which has quite heterogeneous backgrounds. Chronic kidney disease-related bone and mineral disease (CKD-MBD) is defined as "a systemic disorder of mineral and bone metabolism due to CKD, which is manifested by abnormalities in bone and mineral metabolism and/or extraskeletal calcification". Although CKD-MBD is one of the possible causes of osteoporosis, we do not have evidences that CKD-MBD is the only or crucial determinant of bone mechanical strength in CKD patients. The risk of hip fracture is considerably high in CKD patients. Drugs that intervene in systemic mineral metabolism, indeed, lead to the improvement on bone histology in CKD patients. However, it remains unclear whether the intervention in systemic mineral metabolism also improves bone strength, today. Thus, the use of drugs that directly act on bone and the introduction of fracture liaison concept are promising strategies for fragility fracture prevention among CKD patients, as well as treatment for CKD-MBD.
\end{abstract}

Keywords Fragility fracture - Osteoporosis - Chronic kidney disease-related bone and mineral disease (CKDMBD) · Fracture liaison

Junichiro James Kazama

jjkaz@fmu.ac.jp

1 Department of Nephrology and Hypertension, Fukushima Medical University, 1 Hikarigaoka, Fukushima, Fukushima 960-1295, Japan

\section{Introduction}

Various pathological conditions are found in bone among patients with chronic kidney disease (CKD), and the pathophysiological mechanisms that underlie these lesions are also complicated. Here, I briefly review the present condition of fragility bone fracture and its treatment in CKD patients.

\section{Osteoporosis and CKD-MBD}

Osteoporosis is defined by the World Health Organization as "a skeletal disorder characterized by compromised bone strength predisposing to an increased risk of fracture" [1]. This definition omits the following, which had been included in the previous definition [2]; "low bone mass" and "microarchitectural deterioration of bone tissue". The revision clearly indicates that the latter conditions are no longer a requirement or a sufficient condition of osteoporosis. In other words, any bone condition that causes fragility fracture is now considered as osteoporosis. However, the disease definition is frequently misunderstood, because bone mass measurement is still the standard method to diagnose osteoporosis. Although osteoporosis is a disease characterized by compromised bone strength, there is no practical tool to monitor bone mechanical strength at bedside, today. Bone mass is, indeed, a strong determinant of bone mechanical strength [3]; bone mass is used as a diagnosing tool for osteoporosis under the premise that extremely low bone mass could be regarded as a sufficient condition of compromised bone strength.

Since low bone mass is neither a requirement nor a sufficient condition of compromised bone strength, a current diagnosis of osteoporosis is quite inaccurate, which 
could lead to both false-negative and false-positive cases. Yet, we do not have any other practical tools that indicate bone strength, with the exception of a patient's medical history. Thus, bone mass measurement is considered the most powerful tool available today to diagnose osteoporosis.

However, bone mass is not the only determining factor of bone mechanical strength. Factors other than bone mass that determine bone mechanical strength are generally considered aspects of "bone quality" [4]. It has often been said that "bone mechanical strength is predominantly prescribed by bone mass, and bone quality contributes", which seems to be true in most of the cases, but not all the cases. For example, bone mineral density is generally low in elementally school children, and although they fall quite often, they seldom suffer from fragility fractures. Thus, bone quality is sometimes likely to be a more important factor than bone mass for preventing fragility fracture, at least in some patient populations. At present, the ratio of importance of bone mass and bone quality is not clear.

A primary reason for this is that it is difficult to define bone mechanical strength. Because the risk of fragility fracture incidence is also dependent on the risk of fall, it does not strictly represent bone mechanical strength. In ex vivo destruction studies using extracted bone samples, different results will be obtained based on the direction or moment of force applied to the samples. Moreover, bone hardness and viscoelastic properties are different characteristics that contribute independently to the resistance against destruction [5]. Thus, osteoporosis is a heterogeneous disease condition in that many factors contribute to bone fragility with different proportions in each case. The disease background is also quite heterogeneous.

Chronic kidney disease-related bone and mineral disease (CKD-MBD) is defined by the Kidney Disease: Improving Global Outcomes as "a systemic disorder of mineral and bone metabolism due to $\mathrm{CKD}$, which is manifested by abnormalities in bone and mineral metabolism and/or extra-skeletal calcification" [6]. CKD-MBD is a disease consisting of three inter-related components: abnormal laboratory examination results including parathyroid dysfunctions, bone metabolic abnormalities and abnormal soft tissue calcification including vascular calcification. At one time, the term "renal osteodystrophy (ROD)" indicated a disease condition similar to CKD-MBD, but it is now considered simply a pathomorphological feature that indicates bone lesions associated with CKD-MBD [7].

According to the definition of CKD-MBD, bone lesions caused by abnormalities in systemic mineral metabolism associated with CKD are partial features of CKD-MBD, but those lesions do not have to be accompanied by the deterioration of bone mechanical strength. Bone disease with deteriorated mechanical strength is osteoporosis, and
CKD-MBD is one of the possible causative backgrounds of osteoporosis (Fig. 1). However, even in those cases in which CKD-MBD has some roles in the deterioration of bone strength, other factors could also simultaneously contribute to the development of osteoporosis, as osteoporosis has quite heterogeneous backgrounds. We previously advocated a disease concept termed "uremic osteoporosis" that is caused by uremic toxins but not abnormal mineral metabolism [8]. Although many studies are required before understanding this disease condition in detail, it is certain that there are various backgrounds lying behind the bone fragility among patients with CKD. It is, thus, a leap of logic to conclude that CKD-MBD is the only or crucial determinant of bone mechanical strength in CKD patients.

\section{Bone fracture in CKD patients}

It has been confirmed that the hip fracture (HFx) risk is considerably high in dialysis patients in many countries [9-11] including Japan [12]. The risk is 4-13 times higher in dialysis patients compared to the general population. The risk tends to be higher in high-latitude regions in the United States [13]. In Japan, the risk is higher in western prefectures [14], indicating that sunlight has little to do with the HFx risk. Although many investigators consider that the risk is also higher in predialysis CKD patients $[15,16]$, an opposing view has been reported [17]. A few reports contended that the risk of spinal compression fracture is also high in dialysis patients [18].

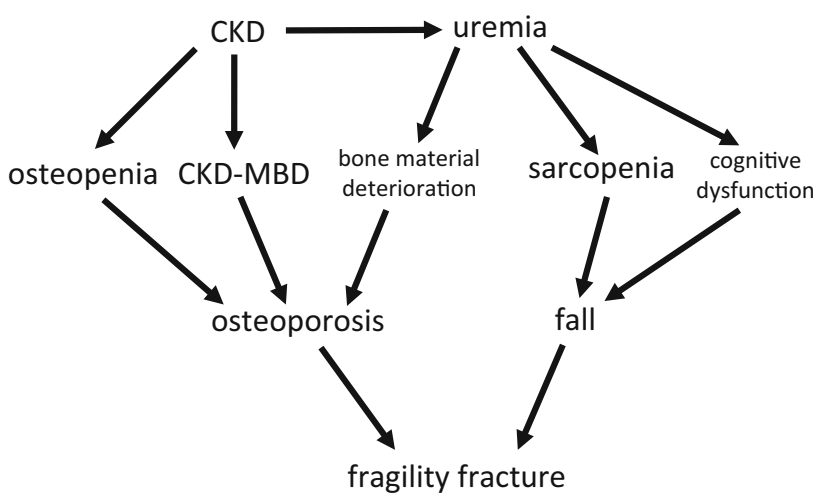

Fig. 1 The pathophysiological mechanism of fragility fracture in CKD patients. Direct cause of fragility fracture is osteoporosis. Generally, the major cause of osteoporosis is osteopenia, and osteopenia is common in CKD patients. Uremia is likely to deteriorate bone material properties. According to the disease concept, bone fragility is not the requirement of CKD-MBD. However, CKD-MBD has a potential to cause osteoporosis. The frequency of the fall is another major risk of fragility fracture, and uremia also increases the risk of fall 
Falls are common in especially elder CKD patients [19], which is very likely to be one of the major causes of elevated HFx risk. Advanced muscle weakness [20], frailty [21], and deteriorated cognition [22] are potential contributors to elevated risk of falling among CKD patients. The survival prognosis generally becomes poorer in patients who have incurred a HFx, and this trend is more evident in dialysis patients [23, 24]. Japanese dialysis patients demonstrated relatively better life prognosis after HFx [25]. However, FRAX, a tool to predict future fracture risk, can predict the risk of mortality even in Japan [26].

It is difficult to know whether being at a high risk of falling is the major cause of the elevated HFx risk in dialysis patients. The majority of clinicians and clinical researchers assume that bone mechanical properties are also deteriorated among dialysis patients. If this assumption is true, many dialysis patients are suffering from osteoporosis.

\section{What happens in bone when kidney is injured?}

The kidney is a pivotal organ for systemic mineral metabolism. When a patient's kidney is injured, the systemic mineral metabolism is affected and the function of bone, which is another pivotal organ for systemic mineral metabolism, is altered through the collapsed feedback system. This is the general idea regarding the development of bone lesions in CKD-MBD.

Among the many humoral factors affecting bone metabolism in disease states, the largest influence is brought by parathyroid hormone (PTH). PTH is secreted by parathyroid gland, which is hyperactivated under CKD conditions. PTH promotes the activity of bone cells, namely osteoblasts, osteocytes and osteoclasts, at microscopic levels. In macroscopic levels, PTH causes cortical thinning and porosis [27] that could result in increased bone fragility. In fact, elevated serum level of alkaline phosphatase, a likely marker for accelerated bone metabolic activity, is reported to be associated with a higher risk of HFx incidence [28]. However, a controversy still remains on the relationship between parathyroid function and structure-related bone strength $[29,30]$. One possible explanation for this issue is that extremely high plasma level of PTH is required to cause evident cortical thinning in dialysis patients [31], because skeletal resistance to PTH stimuli is increased in uremic condition [32-34].

Bone condition that has shown an extremely low frequency of bone remodeling, which is called "adynamic bone" [35] is also observed in dialysis patients, presumably due to increased skeletal resistance. Investigators have speculated that in the adynamic bone condition, the bone mechanical strength could be deteriorated through accumulated microdamages [36]. However, the relationship between bone fragility and each category of the classic ROD classification (Fig. 2) remains unknown. This classification is dependent on bone metabolism but not bone mechanical properties [37].

Treatment for hyperparathyroidism in CKD patients has been greatly improved [38]. Recent clinical studies have obtained controversial results regarding the relationship between PTH and HFx risk [39-42]. The decreased incidence of severe secondary hyperparathyroidism due to the development of medical and surgical treatment seems to have contributed to these unclear results. Moreover, osteomalacia caused by the depositions of aluminum or iron on a skeletal calcified front has been nearly eliminated [43]. Thus, the contribution of CKD-MBD to the development of bone fragility can be expected to have decreased today compared to that in the 1980s. Yet, the HFx risk in dialysis patients has remained extremely high, today. We must, therefore, consider the effect of factors other than CKD-MBD that may promote bone fragility in CKD patients.

Bone mass is regarded as the most important and crucial factor in the prediction of bone mechanical properties in individuals with primary osteoporosis. Bone mass seems to be a major determinant of bone strength among dialysis patients also. In CKD patients, the bone mass starts to decrease at the early predialysis period [44]. Abnormal vitamin $\mathrm{D}$ metabolism, hypoproteinemia, treatments for kidney disease, and parathyroid dysfunction are assumed to be listed as possible causative factors for low bone mass in

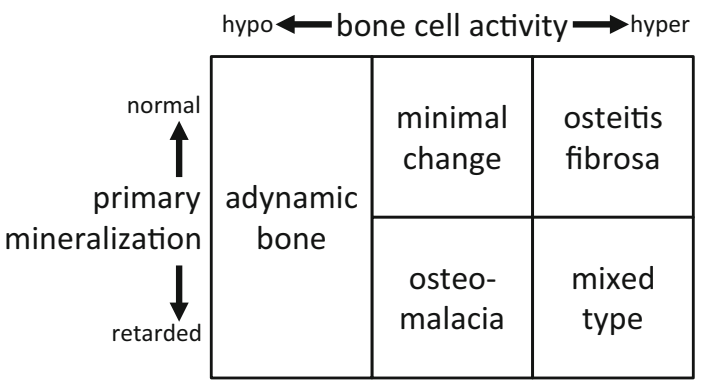

Fig. 2 Classic ROD classification. Histological findings of bone samples obtained by bone biopsy are classified into 5 categories by two assessing axes; bone cell activities and primary mineralization speed. This classification is suitable to evaluate bone metabolic condition in CKD patients because CKD patients demonstrate broad spectrums in these two assessing axes. The logic of this classification is obviously clearer than that of the turnover-mineralization-volume classification, which was advocated subsequently to this classification. However, the need of multifaceted information is recognized for an assessment of bone, and bone histology alone is not capable to meet the need, today. Histological findings obtained from bone sections, in fact, give no information about bone biochemical or mechanical properties, and only limited information about the structural properties. Thus, bone biopsy is not almighty. Considering it as the "gold standard" is an overvaluation 
CKD patients. By the time of dialysis initiation, an individual's bone mineral density is generally low, but the bone mass may not decrease as fast as it did in the predialysis period. The promotion of osteoblast apoptosis was shown to be a likely pathophysiological mechanism through which severe hyperparathyroidism causes extensive bone loss in dialysis patients [45], in addition to the promotion of osteoclastic bone resorption. The clinical significance of bone mass measurement using dual-energy X-ray absorptiometry was not confirmed among dialysis patients [46]. However, recent studies have revealed that lower bone mass is associated with a higher fracture risk even in dialysis patients [47, 48].

Many clinicians/clinical investigators have an impression that bone quality in dialysis patients is deteriorated, although no clear evidence exists on this issue. Bone structural properties that could decrease bone mechanical strength are changed in dialysis patients [49]. In experimental animal models, kidney injury caused the deterioration of bone material properties [50]. In those animals, a viscoelastic property of extracted long bones was deteriorated, and both the modification of type-I collagen with advanced glycation end-products (AGE) and bone apatite disorientation were significantly associated with the deterioration [51]. The deterioration in bone material properties was specifically observed in the uremic condition, but it was not associated with abnormal mineral metabolism. Therefore, strictly speaking, these bone abnormalities cannot be regarded as a feature of CKD-MBD [8]. The AGE-modified type-I collagen was also detected in bone samples obtained from dialysis patients [52].

\section{Fragility fracture prevention in CKD patients}

The original reason for using anti-osteoporotic agents was to strengthen bone mechanical properties, leading to a reduction in the fracture risk. However, most of the existing anti-osteoporotic agents directly act on bone to increase bone mass, and therefore, those drugs are referred to as direct bone metabolic modulators in this manuscript. Bone mass is generally low in CKD patients, and low bone mass increases fracture risk. The use of direct bone metabolic modulators that increase bone mass would, thus, seem to have certain benefit for CKD patients. Although low bone mass is neither a requirement nor a sufficient condition of compromised bone strength, it is certain that increasing bone mass strengthens the bone mechanical property, at least to some extent.

There is a significant limitation regarding the use of direct bone metabolic modulators in patients with kidney dysfunction. Bisphosphonate, which is most commonly applied for treatment against primary osteoporosis, is eliminated through urinary extraction, and there is a risk of bisphosphonate accumulating in bone when it is used for dialysis patients [53]. Accumulated bisphosphonate in bone has the potential to reduce viscoelastic properties [54], which could increase the risk of atypical femoral fracture [55-57]. Because bisphosphonate is highly selectively distributed to bone tissue, it is difficult to monitor its accumulation clinically.

Unlike bisphosphonate, the human monoclonal antibody denosumab does not accumulate even in CKD patients. However, its hypocalcemic action tends to be amplified in CKD patients [58]. It must be in mind that hypocalcemia in dialysis patients directly induces an aggravation of hyperparathyroidism [59]. Although teriparatide is, indeed, effective in some dialysis patients, its vasodilative action often compels a discontinuation of the treatment because it can induce severe hypotension. Regarding the clinical effect of selective estrogen receptor modulators in CKD patients, no clear consensus has been established [60].

CKD-MBD is a consequence of abnormal systemic mineral metabolism. Therefore, drugs that intervene in systemic mineral metabolism are frequently used for a CKD-MBD treatment. Vitamin D receptor activator (VDRA) and calcimimetics may provide a decreased fracture risk by suppressing hyperactivated parathyroid function. These systemic mineral metabolism modulators surely lead to a certain improvement in bone histology; in other words, they change bone metabolism. However, the accurate effects of these agents on bone mechanical properties are not yet verified. VDRA also demonstrates a local action on bone. Long-acting VDRA, such as alfacalcidol [61] or eldecalcitol [62] in particular, have the likely potential to prevent fragility fracture through their own direct actions on bone. A study conducted in the United States indicated that the use of cinacalcet hydrochloride decreased the fracture risk among dialysis patients [63] via a yet unverified mechanism. VDRA and cinacalcet may prevent fragility fracture through intervening in vitamin $\mathrm{K}$ metabolism [64]. Further studies are required to elucidate whether cinacalcet merely intervened in systemic mineral metabolism or also acted directly on bone to provide the decreased fracture risk.

PTH is a humoral factor that affects systemic mineral metabolism; teriparatide was developed to promote bone formation directly by the intermittent use. Yet, no consensus has been established about the indication of teriparatide therapy among CKD patients. The indication may not be confined to those with PTH levels lower than the target range indicated by clinical practice guidelines, because circulating PTH molecules are unlikely to perform full function in CKD patients [65]. The risk of hospitalization due to any fracture among dialysis patients was approximately $30 \%$ lower in the patients treated with an 


\begin{tabular}{|l|l}
$\begin{array}{r}\text { direct } \\
\text { bone }\end{array}$ & $\begin{array}{l}\text { romosozumab } \\
\text { teriparatide } \\
\text { metabolism } \\
\text { modulator }\end{array}$ \\
& $\begin{array}{l}\text { menatetrenone } \\
\text { renin-angiotensin-aldosterone } \\
\text { system inhibitor } \\
\text { raloxifen } \\
\text { eldecalcitol } \\
\text { denosumab }\end{array}$ \\
& $\begin{array}{l}\text { alfacalcidol } \\
\text { cinacalcet }\end{array}$ \\
systemic & \\
mineral & maxacalcitol \\
modulator &
\end{tabular}

Fig. 3 Drugs possibly reduce the risk of fragility fracture among CKD patients

angiotensin-converting-enzyme inhibitor or AT-1 receptor blocker (Renin-Angiotensin-Aldosterone System inhibitor, RAASi) among dialysis patients [66]. Such a phenomenon has not yet been confirmed in a non-CKD population. If bone material properties are truly deteriorated in CKD patients, it is possible that RAASi affect bone material properties by preventing oxidation stress. The serum concentration of bicarbonate ion has a significant relationship with fracture risk [67].

Most of the drugs have more or less both aspects of direct bone metabolism modulator and systemic mineral metabolism modulator (Fig. 3). Although systemic mineral metabolism modulators have been mainly prescribed to CKD patients, the use of direct bone metabolic modulators will be increased in near future from a perspective of fragility fracture prevention.

Most fragility fractures occur due to a fall. The prevention of falls is, thus, another important strategy in fragility fracture prevention, and in fact, it is the most practical tactic at this moment. The so-called fracture liaison concept $[68,69]$ is now gaining attention as an effective tool to prevent fragility fractures among the elderly. Similar attempts should be made for fracture prevention among CKD patients, especially dialysis patients.

\section{Conclusion}

"Osteoporosis is a more severe form of osteopenia". "The bone abnormality observed in CKD patients is CKD-MBD, but not osteoporosis". "Aggressive treatment for CKDMBD is the major strategy for reducing the fragility fracture risk in CKD patients". A close examination of these statements suggests the conclusion that the above propositions are not logically true. However, many clinicians and clinical researchers still seem to believe them [70, 71].
Incorrect assumptions hamper the development and spread of useful treatment by providing meaningless research questions and misleading the interpretation of the evidences obtained. We must deal with fragility fracture prevention among CKD patients with a flexible and logical way of thinking.

Acknowledgements This supplement was supported by grants from The Japanese Society for Kidney Bone Disease (JSKBD) and from the Research Meeting on Kidney and Metabolic Bone Disease.

\section{Compliance with ethical standards}

Conflict of interest JJK has received Grants in Aid from Kissei Pharmaceutical Co., Ltd, and Kyowa Hakko Kirin Co., Ltd.

Open Access This article is distributed under the terms of the Creative Commons Attribution 4.0 International License (http://crea tivecommons.org/licenses/by/4.0/), which permits unrestricted use, distribution, and reproduction in any medium, provided you give appropriate credit to the original author(s) and the source, provide a link to the Creative Commons license, and indicate if changes were made.

\section{References}

1. NIH Consensus Development Panel on Osteoporosis Prevention. Diagnosis, and therapy. osteoporosis prevention, diagnosis, and therapy. JAMA. 2001;285:785-95.

2. Proceedings of a symposium. Consensus development conference on osteoporosis, 19-20 October 1990, Copenhagen. Am J Med 1991; 91:1S-68S.

3. Fujiwara S, Kasagi F, Masunari N, et al. Fracture prediction from bone mineral density in Japanese men and women. J Bone Miner Res. 2003;18:1547-53.

4. Schnitzler CM. Bone quality: a determinant for certain risk factors for bone fragility. Calcif Tissue Int. 1993;53(Suppl 1):S27-31.

5. Yamashita J, Li X, Furman BR, et al. Collagen and bone viscoelasticity: a dynamic mechanical analysis. J Biomed Mater Res. 2002;63:31-6.

6. Moe S, Drüeke T, Cunningham J, et al. Definition, evaluation, and classification of renal osteodystrophy: a position statement from kidney disease: improving global outcomes (KDIGO). Kidney Int. 2006;69:1945-53.

7. Moe SM, Drüeke T. Improving global outcomes in mineral and bone disorders. Clin J Am Soc Nephrol. 2008;3(Suppl 3):S127-30.

8. Kazama JJ, Iwasaki Y, Fukagawa M. Uremic osteoporosis. Kidney Int Suppl. 2011;2013(3):446-50.

9. Alem AM, Sherrard DJ, Gillen DL, et al. Increased risk of hip fracture among patients with end-stage renal disease. Kidney Int. 2000;58:396-9.

10. Lin ZZ, Wang JJ, Chung CR, et al. Epidemiology and mortality of hip fracture among patients on dialysis: Taiwan National Cohort Study. Bone. 2014;64:235-9.

11. Maravic M, Ostertag A, Torres PU, Cohen-Solal M. Incidence and risk factors for hip fractures in dialysis patients. Osteoporos Int. 2014;25:159-65.

12. Wakasugi M, Kazama JJ, Taniguchi M, et al. Increased risk of hip fracture among Japanese hemodialysis patients. J Bone Miner Metab. 2013;31:315-21. 
13. Wetmore JB, Liu J, Wirtz HS, et al. Geovariation in fracture risk among patients receiving hemodialysis. Clin J Am Soc Nephrol. 2016;11:1413-21.

14. Wakasugi M, Kazama JJ, Wada A, et al. Regional variation in hip fracture incidence among Japanese hemodialysis patients. Ther Apher Dial. 2014;18:162-6.

15. Nickolas TL, McMahon DJ, Shane E. Relationship between moderate to severe kidney disease and hip fracture in the United States. Nickolas TL, McMahon DJ, Shane E. J Am Soc Nephrol. 2006; 17:3223-32.

16. Kim SM, Long J, Montez-Rath M, et al. Hip fracture in patients with non-dialysis-requiring chronic kidney disease. J Bone Miner Res. 2016;31:1803-9.

17. Elliott MJ, James MT, Quinn RR, et al. Estimated GFR and fracture risk: a population-based study. Clin J Am Soc Nephrol. 2013;8:1367-76

18. Fusaro M, Tripepi G, Noale M, et al. High prevalence of vertebral fractures assessed by quantitative morphometry in hemodialysis patients, strongly associated with vascular calcifications. Calcif Tissue Int. 2013;93:39-47.

19. Desmet C, Beguin C, Swine C, Jadoul M, Université Catholique de Louvain Collaborative Group. Falls in hemodialysis patients: prospective study of incidence, risk factors, and complications. Am J Kidney Dis. 2005;45:148-53.

20. Stenvinkel P, Carrero JJ, von Walden F, et al. Muscle wasting in end-stage renal disease promulgates premature death: established, emerging and potential novel treatment strategies. Nephrol Dial Transplant. 2016;31:1070-7.

21. Delgado C, Shieh S, Grimes B, et al. Association of self-reported frailty with falls and fractures among patients new to dialysis. Am J Nephrol. 2015;42:134-40.

22. Maravic M, Ostertag A, Urena P, Cohen-Solal M. Dementia is a major risk factor for hip fractures in patients with chronic kidney disease. Osteoporos Int. 2016;27:1665-9.

23. Lin JC, Liang WM. Mortality and complications after hip fracture among elderly patients undergoing hemodialysis. BMC Nephrol. 2015;16:100

24. Kuo $\mathrm{CH}$, Hsieh $\mathrm{TC}$, Wang $\mathrm{CH}$, et al. Increased risks of mortality and atherosclerotic complications in incident hemodialysis patients subsequently with bone fractures: a nationwide casematched cohort study. PLoS One. 2015;10:e0121705.

25. Tentori F, McCullough K, Kilpatrick RD, et al. High rates of death and hospitalization follow bone fracture among hemodialysis patients. Kidney Int. 2014;85:166-73.

26. Hayashi T, Joki N, Tanaka Y, et al. The FRAX ${ }^{\circledR}$ as a predictor of mortality in Japanese incident hemodialysis patients: an observational, follow-up study. J Bone Miner Metab. 2015;33:674-83.

27. Nickolas TL, Stein EM, Dworakowski E, et al. Rapid cortical bone loss in patients with chronic kidney disease. J Bone Miner Res. 2013;28:1811-20.

28. Maruyama Y, Taniguchi M, Kazama JJ, et al. A higher serum alkaline phosphatase is associated with the incidence of hip fracture and mortality among patients receiving hemodialysis in Japan. Nephrol Dial Transplant. 2014;29:1532-8.

29. Negri AL, Del Valle EE, Zanchetta MB, et al. Evaluation of bone microarchitecture by high-resolution peripheral quantitative computed tomography (HR-pQCT) in hemodialysis patients. Osteoporos Int. 2012;23:2543-50.

30. Trombetti A, Stoermann C, Chevalley T, et al. Alterations of bone microstructure and strength in end-stage renal failure. Osteoporos Int. 2013;24:1721-32.

31. Kazama JJ, Matsuo K, Iwasaki Y, Fukagawa M. Chronic kidney disease and bone metabolism. J Bone Miner Metab. 2015;33:245-52.
32. Fukagawa M, Kazama JJ, Shigematsu T. Skeletal resistance to PTH as a basic abnormality underlying uremic bone diseases. Am J Kidney Dis. 2001;38(4 Suppl 1):S152-5.

33. Fukagawa M, Iwasaki Y, Kazama JJ. Skeletal resistance to parathyroid hormone as a background abnormality in uremia. Nephrology. 2003;8(Suppl):S50-2.

34. Iwasaki Y, Yamato H, Nii-Kono T, et al. Insufficiency of PTH action on bone in uremia. Kidney Int Suppl. 2006;102:S34-6.

35. Malluche HH, Monier-Faugere MC. Risk of adynamic bone disease in dialyzed patients. Kidney Int Suppl. 1992;38:S62-7.

36. Seref-Ferlengez Z, Kennedy OD, Schaffler MB. Bone microdamage, remodeling and bone fragility: how much damage is too much damage? Bonekey Rep. 2015;4:644.

37. Kazama JJ. Bone histology in chronic kidney disease-related mineral and bone disorder. Ther Apher Dial. 2011;15(Suppl 1):23-5.

38. Komaba H, Shiizaki K, Fukagawa M. Pharmacotherapy and interventional treatments for secondary hyperparathyroidism: current therapy and future challenges. Expert Opin Biol Ther. 2010;10:1729-42.

39. Block GA, Klassen PS, Lazarus JM, et al. Mineral metabolism, mortality, and morbidity in maintenance hemodialysis. J Am Soc Nephrol. 2004;15:2208-18.

40. Stehman-Breen CO, Sherrard DJ, Alem AM, et al. Risk factors for hip fracture among patients with end-stage renal disease. Kidney Int. 2000;58:2200-5.

41. Danese MD, Kim J, Doan QV, et al. PTH and the risks for hip, vertebral, and pelvic fractures among patients on dialysis. Am J Kidney Dis. 2006;47:149-56.

42. Coco M, Rush H. Increased incidence of hip fractures in dialysis patients with low serum parathyroid hormone. Am J Kidney Dis. 2000;36:1115-21.

43. Chappard D, Bizot P, Mabilleau G, Hubert L. Aluminum and bone: review of new clinical circumstances associated with $\left.\mathrm{Al}^{3+}\right)$ deposition in the calcified matrix of bone. Morphologie. 2016;100:95-105.

44. Aggarwal HK, Jain D, Yadav S, Kaverappa V. Bone mineral density in patients with predialysis chronic kidney disease. Ren Fail. 2013;35:1105-11.

45. Kazama JJ, Yamamoto S, Narita I, Kurihara S. Nuclear chromatin-concentrated osteoblasts in renal bone diseases. Ther Apher Dial. 2011;15(Suppl 1):9-13.

46. Ott SM. Bone density in patients with chronic kidney disease stages 4-5. Nephrology. 2009;14:395-403.

47. Iimori S, Mori Y, Akita W, et al. Diagnostic usefulness of bone mineral density and biochemical markers of bone turnover in predicting fracture in CKD stage 5D patients-a single-center cohort study. Nephrol Dial Transplant. 2012;27:345-51.

48. Yenchek RH, Ix JH, Shlipak MG, et al. Bone mineral density and fracture risk in older individuals with CKD. Clin J Am Soc Nephrol. 2012;7:1130-6.

49. Cejka D, Patsch JM, Weber M, et al. Bone microarchitecture in hemodialysis patients assessed by HR-pQCT. Clin J Am Soc Nephrol. 2011;6:2264-71.

50. Iwasaki Y, Kazama JJ, Yamato H, Fukagawa M. Changes in chemical composition of cortical bone associated with bone fragility in rat model with chronic kidney disease. Bone. 2011;48:1260-7.

51. Iwasaki Y, Kazama JJ, Yamato H, et al. Altered material properties are responsible for bone fragility in rats with chronic kidney injury. Bone. 2015;81:247-54.

52. Mitome J, Yamamoto $H$, Saito $M$, et al. Nonenzymatic crosslinking pentosidine increase in bone collagen and are associated with disorders of bone mineralization in dialysis patients. Calcif Tissue Int. 2011;88:521-9. 
53. Ott SM. Bisphosphonate safety and efficacy in chronic kidney disease. Kidney Int. 2012;82:833-5.

54. Güerri-Fernández RC, Nogués X, Quesada Gómez JM, et al. Microindentation for in vivo measurement of bone tissue material properties in atypical femoral fracture patients and controls. J Bone Miner Res. 2013;28:162-8.

55. Shane E, Burr D, Abrahamsen B, et al. Atypical subtrochanteric and diaphyseal femoral fractures: second report of a task force of the American Society for Bone and Mineral Research. J Bone Miner Res. 2014;29:1-23.

56. Mahjoub Z, Jean S, Leclerc JT, et al. Incidence and characteristics of atypical femoral fractures: clinical and geometrical data. J Bone Miner Res. 2016;31:767-76.

57. Sato H, Kondo N, Wada Y, et al. The cumulative incidence of and risk factors for latent breaking in patients with autoimmune diseases taking long-term glucocorticoids and bisphosphonates. Osteoporos Int. 2016;27:1217-25.

58. Okada N, Kawazoe K, Teraoka K, et al. Identification of the risk factors associated with hypocalcemia induced by denosumab. Biol Pharm Bull. 2013;36:1622-6.

59. Chen CL, Chen NC, Hsu CY, et al. An open-label, prospective pilot clinical study of denosumab for severe hyperparathyroidism in patients with low bone mass undergoing dialysis. J Clin Endocrinol Metab. 2014;99:2426-32.

60. Nagatoya K, Nishimoto K, Shibahara N, et al. Effects of raloxifene on bone metabolism in postmenopausal women on chronic hemodialysis. Clin Exp Nephrol. 2015;19:939-46.

61. Dey V, Farrah TE, Traynor JP, et al. Symptomatic fracture risk in the renal replacement therapy population. Nephrol Dial Transplant. 2016 (in press; epub ahead of print).

62. Sasaki N, Tsunoda M, Ikee R, Hashimoto N. Efficacy and safety of eldecalcitol, a new active vitamin D3 analog, in the bone metabolism of postmenopausal women receiving maintenance hemodialysis. J Bone Miner Metab. 2015;33:213-20.

63. Moe SM, Abdalla S, Chertow GM, et al. Effects of cinacalcet on fracture events in patients receiving hemodialysis: the EVOLVE Trial. J Am Soc Nephrol. 2015;26:1466-75.

64. Fusaro M, Giannini S, Gallieni M, et al. Calcimimetic and vitamin D analog use in hemodialyzed patients is associated with increased levels of vitamin $\mathrm{K}$ dependent proteins. Endocrine. 2016;51:333-41.

65. Hocher B, Armbruster FP, Stoeva S, et al. Measuring parathyroid hormone (PTH) in patients with oxidative stress-do we need a fourth generation parathyroid hormone assay? PLoS One. 2012; 7:e40242.

66. Yamamoto S, Kido R, Onishi Y, et al. Use of renin-angiotensin system inhibitors is associated with reduction of fracture risk in hemodialysis patients. PLoS One. 2015;10:e0122691.

67. Kato A, Kido R, Onishi Y, et al. Association of serum bicarbonate with bone fractures in hemodialysis patients: the mineral and bone disorder outcomes study for Japanese CKD stage 5D patients (MBD-5D). Nephron Clin Pract. 2014;128:79-87.

68. Giles M, Van Der Kallen J, Parker V, et al. A team approach: implementing a model of care for preventing osteoporosis related fractures. Osteoporos Int. 2011;22:2321-8.

69. Leal J, Gray AM, Hawley S, et al. Cost-effectiveness of orthogeriatric and fracture liaison service models of care for hip fracture patients: A population based study. J Bone Miner Res. 2016 (in press; epub ahead of print).

70. Salam SN, Eastell R, Khwaja A. Fragility fractures and osteoporosis in CKD: pathophysiology and diagnostic methods. Am J Kid Dis. 2014;63:1049-59.

71. Miller PD. Chronic kidney disease and osteoporosis: evaluation and management. Bonekey Rep. 2014;3:542. 